\title{
Espaço e tempo na Amazônia Setentrional: a gênese da formação territorial do Estado de Roraima
}

\author{
Espacio y tiempo en la amazonia sientrional: la génese de la \\ formación territorial del Estado de Roraima
}

\section{Lúcio Keury Almeida Galdino, Edson Vicente da Silva² e Adryane Gorayeb ${ }^{3}$}

\begin{abstract}
1 Professor do Curso de Geografia da Universidade Estadual de Roraima-UERR. Doutor em Geografia pela Universidade Federal do Ceará-UFC. E-mail: Ikagaldino@yahoo.com.br

2 Professor Titular do Curso de Geografia da Universidade Federal do Ceará-UFC. Pós-doutor em Planejamento e Geoecologia das Paisagens pela Faculdade de Geografia, Universidade de Havana-Cuba. E-mail: cacauceara@gmail.com

3 Professora do Curso de Geografia da Universidade Federal do Ceará - UFC. Doutora em Geografia pela Universidade Estadual de São Paulo (UNESP-Rio Claro). E-mail: adryanegorayeb@yahoo.com.br
\end{abstract}

RESUMO: A colonização portuguesa (séculos XV e XIX), marcou um período de conquistas e conflitos no território brasileiro, visava a exploração natural e humana. Atualmente, os estados da Amazônia vêm atraindo discussões, debates e produções científicas nos diversos campos acadêmicos, ao mesmo tempo em que se contextualizam questões sociais, culturais, territoriais e ambientais, objetivando entender o início da formação territorial de Roraima, baseando-se em informações bibliográficas, pesquisas de campo, registros/documentos historiográficos e fotos. Metodologicamente, usou-se recortes históricos sobre Rio Branco e da questão indígena. Os resultados remetem-se ao entendimento da formação do território e entender a sua atual organização social.

Palavras-chave: Colonização. Indígenas. Território. Roraima.

\begin{abstract}
The Portuguese colonization (centuries XV and XIX), marked a period of conquest and conflict in the Brazilian territory, aimed at natural and human exploration. At present, the Amazonian states are attracting discussions, debates and scientific productions in the various academic fields, while contextualizing social, cultural, territorial and environmental issues, aiming to understand the beginning of the territorial formation of Roraima, basing itself on information bibliographies, field surveys, historiographical records and documents, and photos. Methodologically, historical cuttings were used on Rio Branco and the indigenous question. The results refer to the understanding of the formation of the territory and to understand its current social organization,
\end{abstract}

Keywords: Colonization. Indigenous people. Territory. Roraima.

Sumário: Introdução - 1 A Região do Rio Branco e os Indígenas: A Gênese Territorial do Estado de Roraima - 2 Boa Vista: de Fazenda à Município - Considerações Finais - Referências. 


\section{INTRODUÇÃO}

Com a chegada dos europeus na América, a vida dos índios começou a se modificar e o seu território passou a ter proporções reduzidas devido aos conflitos/conquistas territoriais dos "chegados", bem como o número da sua população. Apropriando-se da "demografia hipotética", estima-se que antes dos europeus conquistarem o "Novo Mundo", em especial, uma considerável porção da América Latina, no século XV, a população indígena apresentava uma marca aproximada de 93 milhões de habitantes, segundo cruzamentos de informações nas obras Veias Abertas da América Latina e o Povo Brasileiro, como segue a Tabela 01.

Tabela 01: Valores aproximados da população indígena na América Latina (Séc. XV).

\begin{tabular}{ll}
\hline LOCALIDADES & QUANTIDADE \\
\hline México (Pré-colombiano) & 37,5 milhões de habitantes \\
\hline Região Andina & 37,5 milhões de habitantes \\
\hline América Central & 13 milhões de habitantes \\
\hline Brasil & 5 milhões de habitantes \\
\hline TOTAL & 93 milhões de habitantes \\
\hline
\end{tabular}

Fonte: Adaptado de Galeano, 1977 \& Ribeiro, 1995. Elaborada pelos autores.

A violência a esses povos, sem dúvida, deixava claro a vulnerabilidade deles perante o poder bélico dos "chegados" que ali legitimavam uma conquista territorial. Sem sombra de dúvidas, os índios da Terra de Vera Cruz, não conheciam a escrita, a linguagem e a cultura do chamado "Velho Mundo", portanto não podiam prever que o invasor europeu tentaria provocar mudanças em seus hábitos e costumes. Nesse sentido, o território brasileiro ficou marcado, de Norte a Sul, por essas tais conquistas territoriais e na Região Amazônica, em especial, na Região do Rio Branco não foi diferente.

O presente artigo faz um recorte espaço-temporal, entre os séculos (XVII - XIX), com ênfase sobre a gênese do Estado de Roraima, localiza-se na porção setentrional da região amazônica (Figura 01), onde este é reconhecido no Brasil e no mundo, pela forte presença no contexto indígena e ambiental.

Pode-se destacar que, o estado tem sua etimologia linguística ligada ao termo Roro-imã que possui diferentes significados. Nesta perspectiva, Roraima (2008), afirma que na língua dos Macuxi, por exemplo, significa Monte Verde e para os índios Pémon e Taurepang, quer dizer Mãe dos Ventos. Os diferentes significados deixam claramente expresso que esse estado tem um forte elo com a cultura indígena e que, apesar da miscigenação das raças, os índios têm um papel fundamental na composição do povo roraimense, pois representa cerca de $11,18 \%$ da população do Estado de Roraima, o que equivale a 50.449 indígenas (CAMPOS, 2011). 
Figura 01: Localização Geográfica do Estado de Roraima
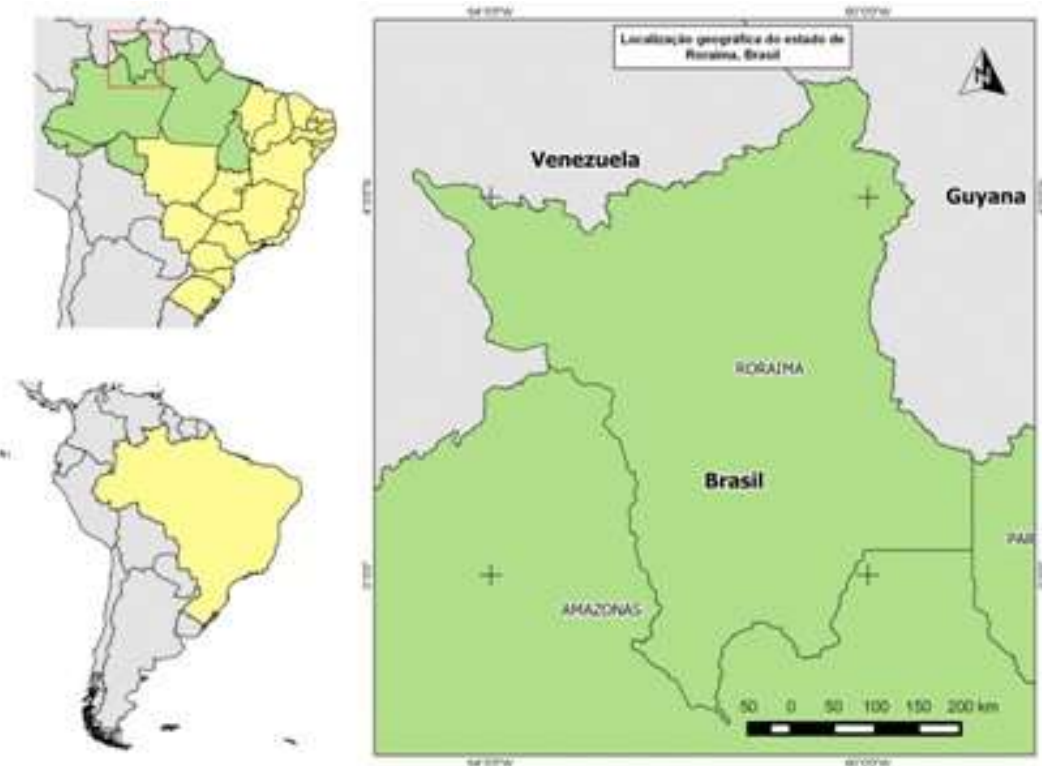

Fonte: MMA/FUNAI, 2015. Elaborado pelos autores.

Conforme o Instituto Brasileiro de Geografia e estatística (IBGE, 2010), o Estado de Roraima (Figura 02) tem em seu território 15 municípios compreendendo uma área total de 224.298,980 $\mathrm{Km}^{2}$ e uma população absoluta de 451.227 habitantes.

Figura 02: Mapa do Estado de Roraima.
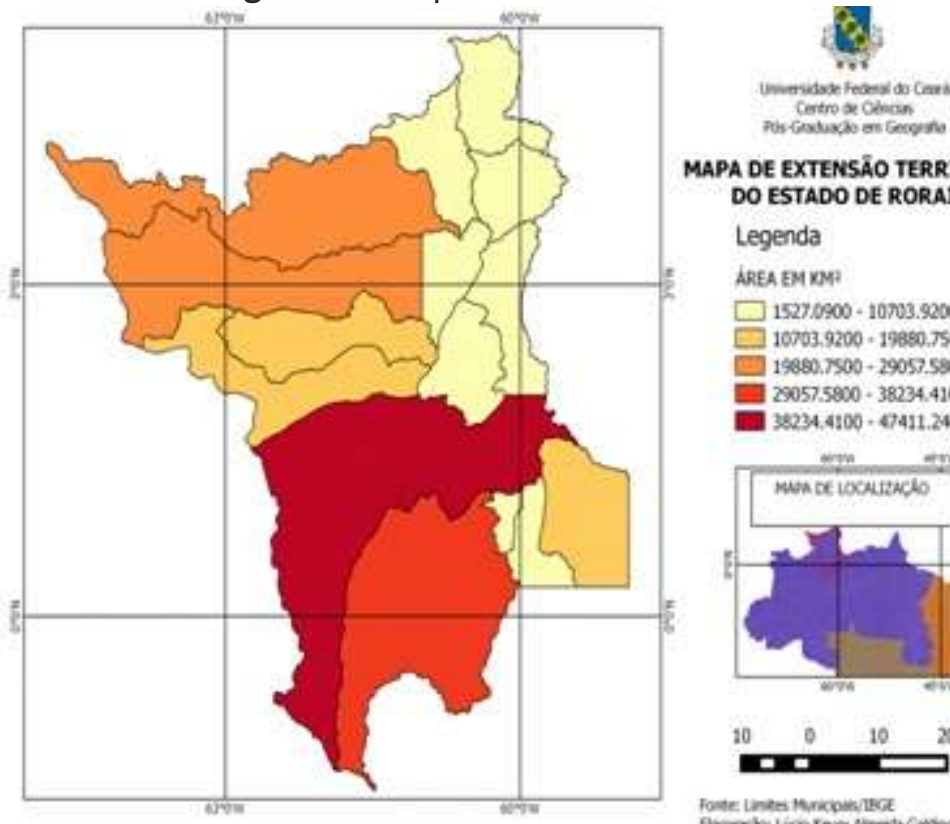

MAPA DE EXTENSÃO TERRTTORIAL DO ESTADO DE RORAIMA

Legenda

AREA EM KM:

$\square 1527.09000-10703.9200$

$10703,9200-19280.7500$

$19800.7500+29057.5900$

믈 $20057.5900-38234.4100$

- $32234.4500 \cdot-8441.2400$
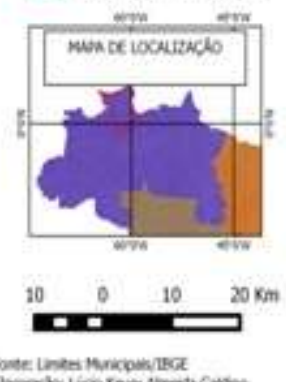

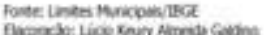

Fonte: IBGE, 2010. Elaborada pelos autores.

Ainda neste espaço geográfico, observa-se a presença de oito povos indígenas transfronteiriços (Brasil-Guiana-Venezuela) e 40 áreas protegidas (32 Terras Indígenas/TI que so-

Planeta Amazônia: Revista Internacional de Direito Ambiental e Políticas Públicas 
mam 46.3\% da área de Roraima e oito Unidades de Conservação Federais, das quais duas são de uso sustentável e seis de proteção integral, que somam 6.6 \%) (CAMPOS, 2011).

\title{
1 A REGIÃO DO RIO BRANCO E OS INDÍGENAS: A GÊNESE TERRITORIAL DO ESTADO DE RO- RAIMA
}

As primeiras notícias relatadas, oficialmente, da região do Rio Branco, no Brasil, ocorrem na década de 30 do século XVII, quando Pedro Teixeira, na ocasião, fazia uma expedição, comandada pelo Capitão Pedro Teixeira, na bacia do rio Negro, onde estava localizada, no médio Amazonas, a Capitania de São José do Rio Negro. Ele adentra em um afluente de águas sedimentares, que logo após o batiza de rio Branco. Com as incursões na região do Rio Branco, os portugueses percebem, nas margens do rio, a presença de índios e logo inicia a tentativa de escravizá-los (FERRI, 1990).

Vale mencionar que nesse momento histórico ocorreu um deslocamento de indígenas para o interior, como relata Ferri, na sua obra Achados ou Perdidos? A Migração Indígena em Boa Vista.

\begin{abstract}
Não só a penetração das "tropas de resgate", que tinham a função de capturar os índios para serem escravizados, como também a invasão por parte de holandeses, ingleses e espanhóis e a implantação de missões e prelazias deram início a um processo irreversível de contato interétnico. Isso promoveu não apenas o deslocamento de alguns desses grupos para outras áreas, mas também o aliciamento, a dizimação e, finalmente, a tentativa de civiliza-los (FERRI, 1990, p. 13).
\end{abstract}

No que tange a ocupação do território do Rio Branco, a Coroa Portuguesa, na preocupação de defender a sua "mais nova" territorialidadade amazônica da expansão colonial espanhola e holandesa, incumbiu ao Estado do Grão-Pará à edificação do Forte São Joaquim do Rio Branco, conhecido como Forte São Joaquim (Figura 03), que ficava às margens do rio Branco (ano de 1778) com a função de defender a região das invasões e explorações dos europeus quanto aos recursos naturais (drogas do sertão) da Amazônia Ocidental, onde fica nas proximidades da confluência dos rios Uraricoera e Tacutú (PAVANI; MOURA, 2006). 
Figura 03: Forte São Joaquim ${ }^{1}$

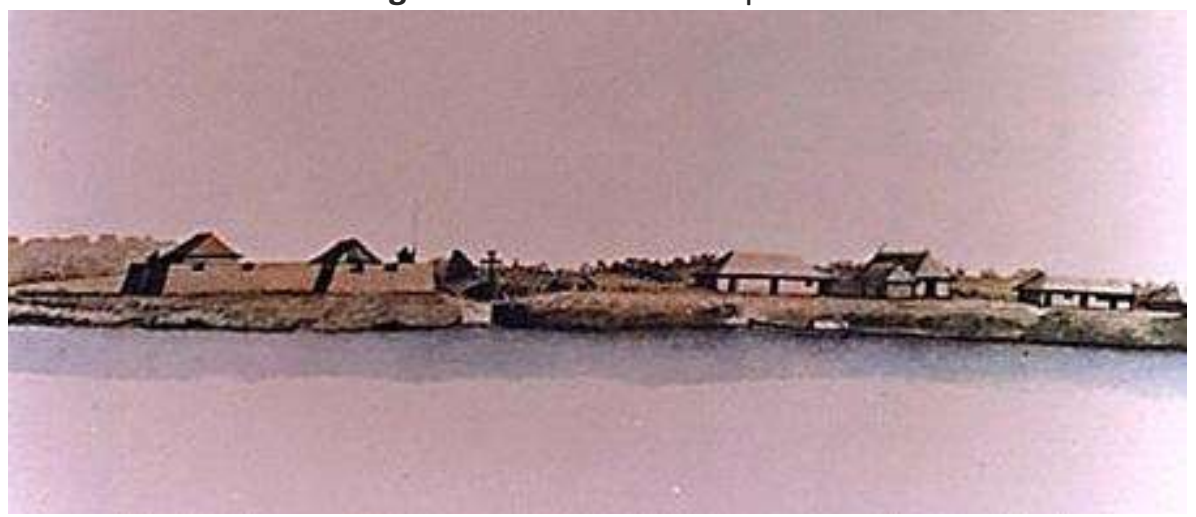

Fonte: Acervo de Waldir Paixão apud VERAS, 2009.

Com a necessidade de proteger as terras do Rio Branco, o Capitão Nicolau de Sá Sarmento recebe a missão de comandar o Forte e anos mais tarde surgem as Fazendas Reais/Nacionais. Com a função de provocar o povoamento da região, foi fundada por ele, o comandante do Forte (Figura 04). Apesar da primeira Fazenda Nacional criada foi a São Bento, cabe destacar que o primeiro aldeamento deu início no entorno da Fazenda Nacional São Marcos e essa estratégia logo se estendeu por todo o curso do rio Branco na tentativa de garantir a segurança e a "posse" do território aos portugueses.

Nesse sentido, Araújo \& Pinto afirma que:

No fim de 1777, havia na região cinco povoados: São Felipe, na margem oriental do Tacutú, perto do Forte; Nossa Senhora da Conceição, o mais populoso, localizado a dois dias do Forte no Uraricoera; Santa Bárbara, no rio Branco, a três horas de barco do Forte; Santa Isabel, também no rio Branco, a seis horas do Forte, bem mais ao sul; Nossa Senhora do Carmo que muito depois tornou-se a cidade de Boa Vista. Na época, eram aproximadamente 1.019 índios aldeados nas cinco povoações existentes (2008, p. 13-14).

\footnotetext{
${ }^{1}$ Aquarela feita durante a expedição comandada por Alexandre Rodrigues Ferreira \Séc. XVIII.
} 
Figura 04: A) Carta imagem do Alto rio Branco; B) Foto da Fazenda Nacional São Marcos em ruinas; C) Foto do alto curso do rio Branco; D) Local do Forte São Joaquim

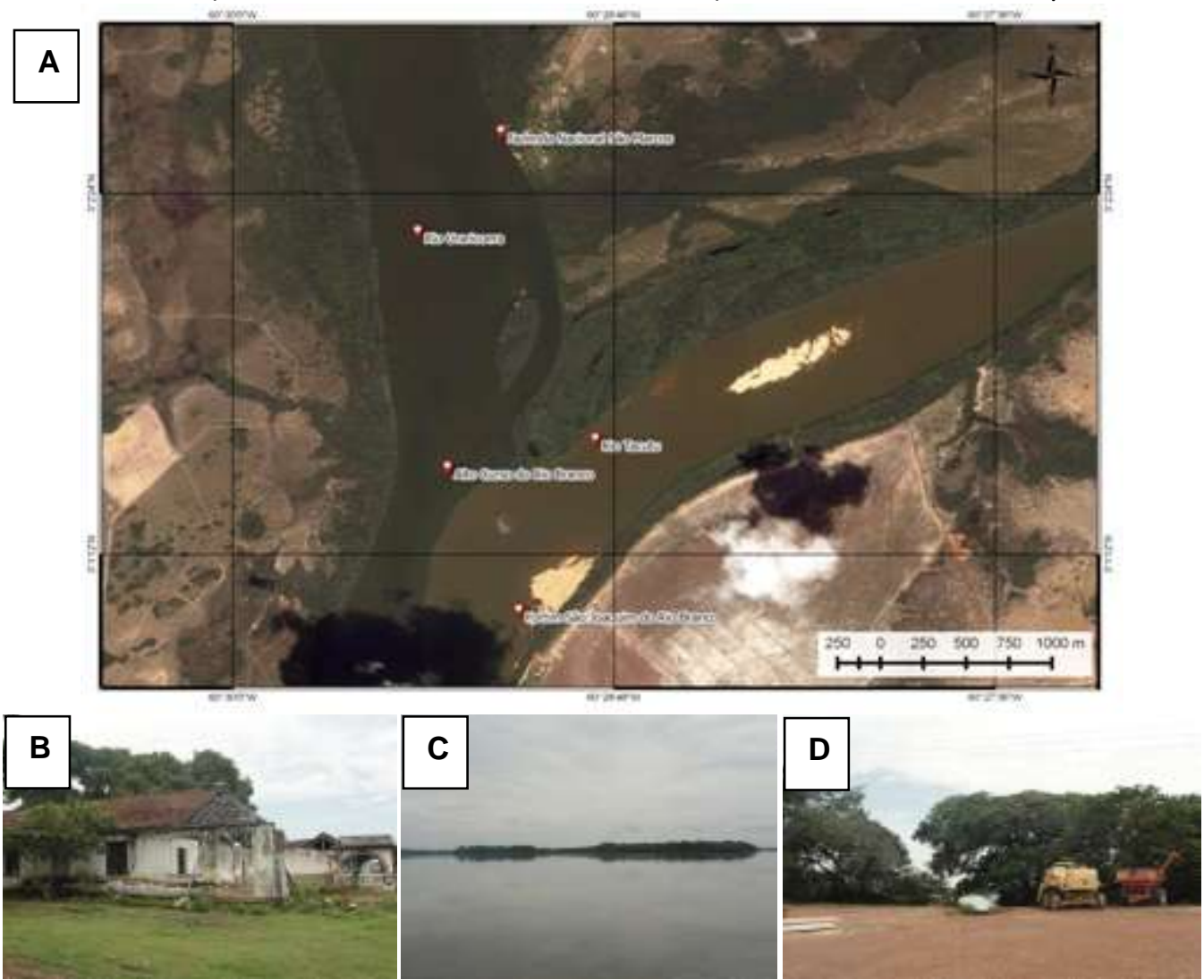

Fonte: Google Earth, 2015. Elaborada pelos autores, Fotos: Autores, 2014.

Essa medida foi criada para assegurar as investidas missões de europeus de reconhecimento e extração (dos campos: se obtinham madeiras e resinas apreciadas, além da baunilha, cacau e salsaparrilha; e dos rios: a pesca e a viração das tartarugas) já que existiam relatos documentais da passagem de estrangeiros na região (FARAGE, 1991).

Porém, na década de 80 do século XVIII, a ideia dos portugueses em formar aldeamentos começa a fracassar, uma vez que os índios recebiam maus tratos dos diretores e soldados das aldeias, além da falta de alimentos para abastecê-las e quando não, ocorria o estranhamento da base alimentar indígena (a farinha) e estes começavam a abandonar o local, tendo em vista que não era difícil fugir. Na mesma década, uma expedição a serviço da Coroa Portuguesa contatou com o tuxaua Annanaly que fora "agradado" sob condição de retornar com seu povo Makusi (Macuxi) ao aldeamento do Forte (ARAÚJO; PINTO, 2008 \& FARAGE, 1991).

Em 1787, o Capitão Lobo D’almada, Governador da Capitania do Rio Negro, visitou a região do Rio Branco e presenciou a reconstituição dos aldeamentos que segundo Araújo \& Pinto $(2008$, p. 14) "[...] viviam então nos povoados 931 índios, em sua maioria casados e com filhos [...] no de Nossa Senhora da Conceição, o mais populoso, viviam duzentos e oitenta e seis índios e seis brancos [...]".

Ainda Araújo \& Pinto (2008), Lobo D’almada sugere aos portugueses a migração de pessoas de outras partes do Brasil com o objetivo de implantar a pecuária bovina e que isso im- 
plicaria atrair e civilizar os indígenas através do contato com os brancos. Nesse sentido, Lobo D’almada utilizou-se de uma estratégia, conforme Araújo \& Pinto relata que:

a) Persuadir os índios das vantagens do sistema de vida português e por isso, "sustenta-los, vesti-los, não os fadigar"; b) dar o que se promete e pagá-los "prontamente e sem usura"; c) deixar que cultivem as próprias roças e alimentarem-se segundo os seus costumes; d) não obriga-los a trabalhos forçados; e) não arrancar os filhos e as mulheres das famílias; f) favorecer o casamento entre soldados e índias, até incentivando-os com donativos e vacas (2008, p. 14).

Com o povoamento de brancos e índios, o governador da província do Rio Negro garante um novo projeto que firmaria, na região do Rio Branco, a criação das Fazendas Nacionais, são elas: de São Bento (1789), São Marcos (1794) e São José (1799) (Figura 05). Com essas fazendas, são introduzidos os primeiros núcleos de gado bovino e, no final do século XVIII, a soma desses, nas três fazendas, não ultrapassava de um milhar, estando trezentos na Fazenda Nacional São Marcos (ARAÚJO; PINTO, 2008).

Figura 05: Localização das Fazendas Nacionais

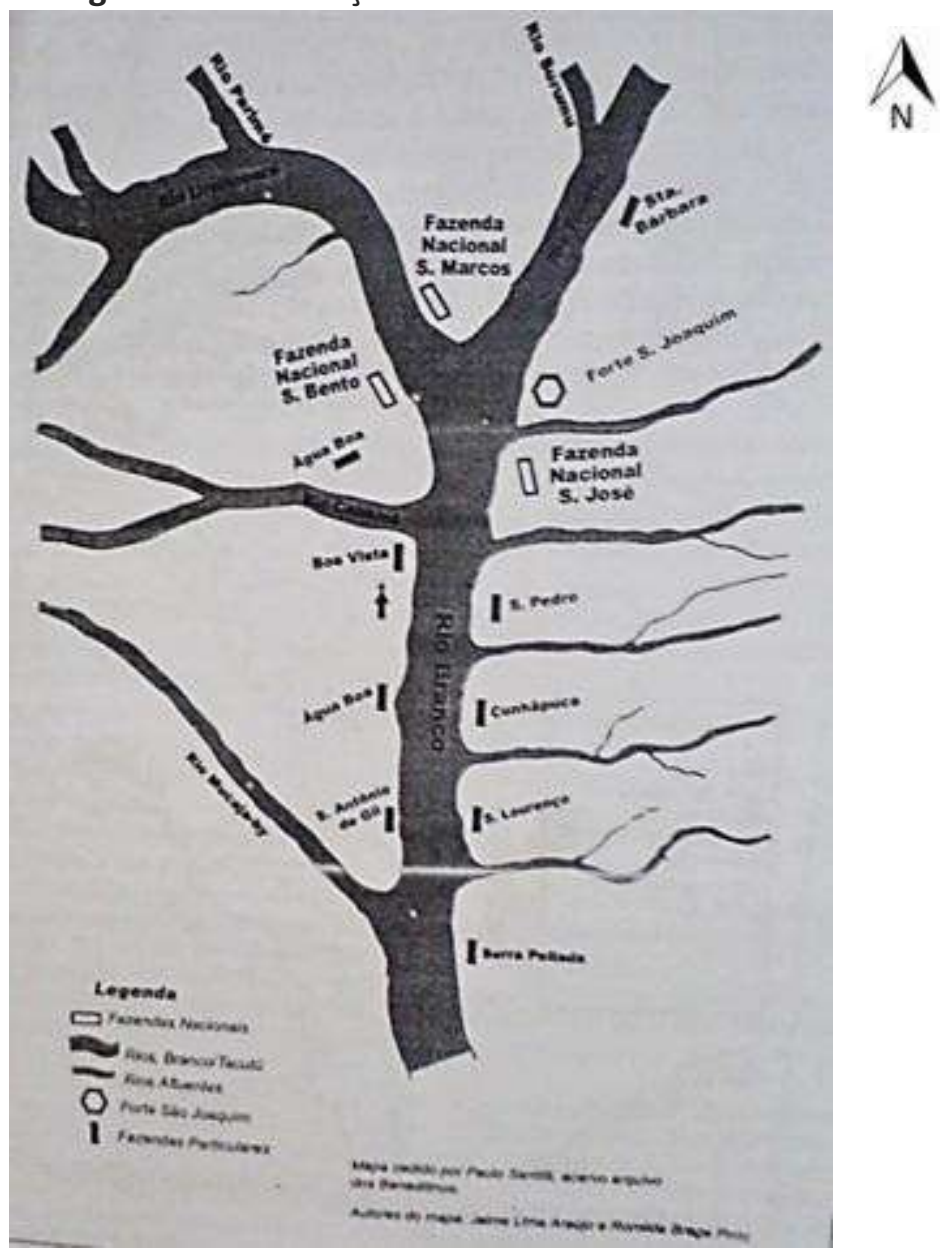

Fonte: Araújo e Pinto (2008).

Foi com base nessa economia, oscilante (apogeu e decadência), que a Fazenda de Boa 
Vista surgiu (em 1830) e iniciou assim um processo de migração e consequentemente de expansão territorial. Corroborando, Silva diz que:

\begin{abstract}
Essas fazendas nacionais tiveram seu tempo áureo, mas entraram em decadência, como é o caso da fazenda São José, que foi anexada a fazenda São Marcos e tinha tido sua sede como a povoação sede do forte de São Joaquim [...] Assim, foram criadas fazendas particulares por militares do forte e por imigrantes que se deslocavam de outras regiões do Norte e do Nordeste brasileiro, entre elas, a Fazenda Boa Vista, fundada em 1830, às margens do rio Branco (2007, p. 95).
\end{abstract}

Em meados da segunda metade do século XIX e com caráter de desenvolver, social e economicamente, a região do Médio rio Branco, a fazenda Boa Vista foi fundada pelo então oficial do Forte São Joaquim (Inácio Lopes Magalhães) que recém-chegado do Ceará vislumbrou-se com a potencialidade ambiental da área e fundou a Fazenda Boa Vista (PAVANI; MOURA, 2006).

Cabe destacar que a população que habitava os entornos das Fazendas Nacionais no início do século XIX era de sua maioria indígena. Porém, com o incentivo da criação bovina, ocorre a penetração dos homens brancos (os não-índios) pela região do Rio Branco (GUERRA apud VERAS, 2009).

Ressalva-se, então, a importância dos nordestinos que, afugentados pelas sucessivas secas do semiárido, migraram para a região (Fazenda de Boa Vista), de forma espontânea, e logo se fixaram e juntos com os nativos colaboraram com a mão de obra que fortaleceu o crescimento da pecuária na região, onde recebeu a responsabilidade de abastecer, com gado, a região do Rio Negro e Alto Amazonas (VALE, 2005).

O meio natural foi propício à criação da fazenda, tendo em vista que o lugar é marcado pela presença de um imenso corpo hídrico (rio Branco), um campo natural com várzeas e lagoas (para pastagem) e os buritizais que decoram a paisagem do chamado "lavrado roraimense" (Figura 06).

Nesse sentido, tem-se um lugar propício ao desenvolvimento pecuário que colaborou para uma dinâmica colonizadora assim pensada (e citado anteriormente) pelo então governador Lobo D’almada no objetivo, primário, de proteger o território contra invasões de europeus.

O projeto das três Fazendas Nacionais não se prolongou como se desejava. Todavia, obteve-se o valor de implantar nessa área de campo a criação de gado, atividade que até meados do século XVIII era inteiramente desconhecida (GUERRA apud VERAS, 2009). 
Figura 06: A) Foto panorâmica do médio curso do rio Branco; B) Foto panorâmica da vegetação de campos com lagoa; C) Foto panorâmica de campos com presença de serra e vegetação arbustiva

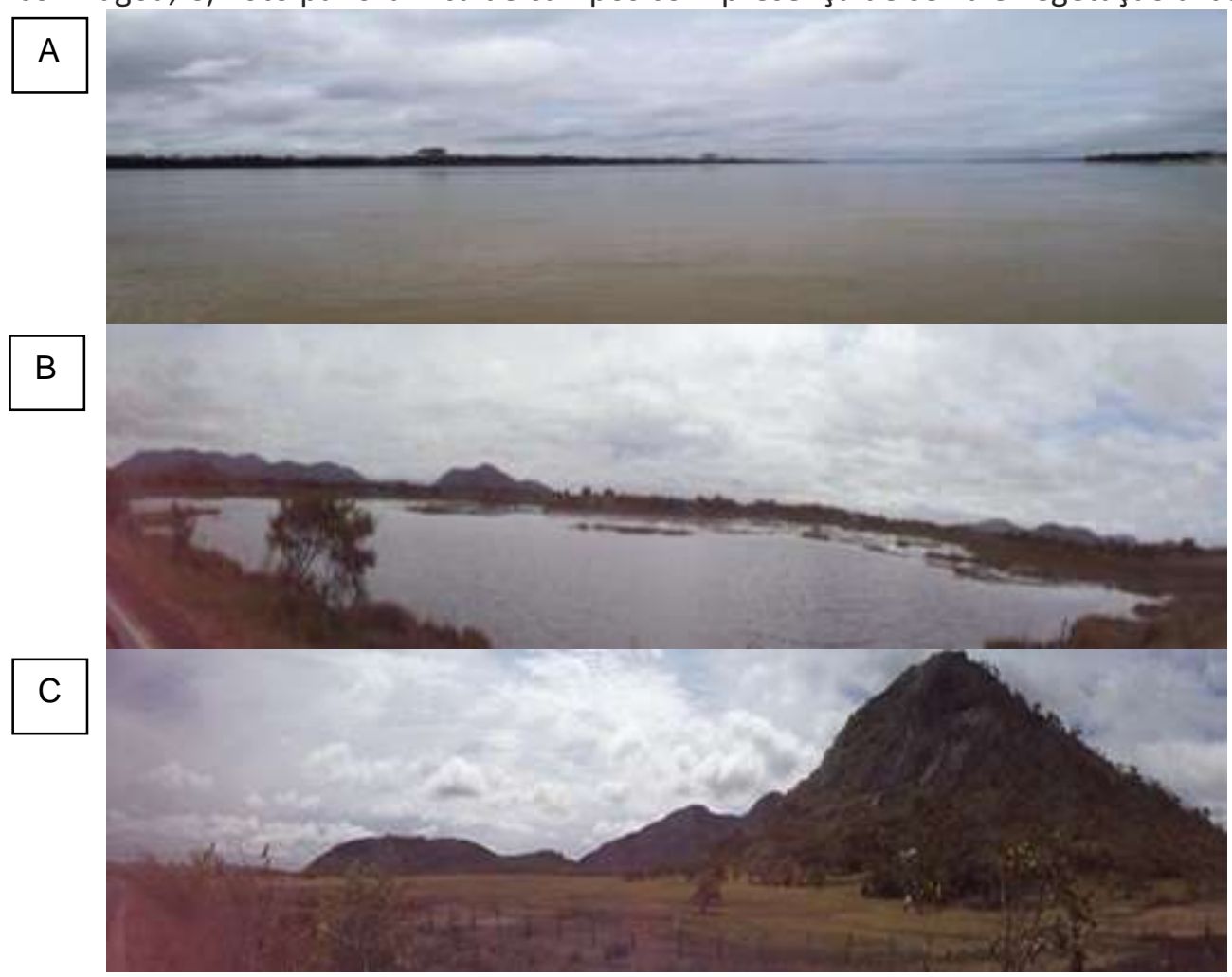

Fonte: Autores, 2014.

O surgimento das fazendas nos campos do rio Branco gerou uma tentativa de manter uma atividade econômica tradicional que, no transcorrer dos séculos XVIII ao XX, permitiria a fixação dos grupos migrantes na região, tendo como consequência a implantação de estruturas semelhantes ao do Sistema Feudal da Idade Média (BARBOSA, 1993). As estruturas implantadas eram comandadas pelos patriarcas das famílias mais influentes da região, que, exerciam o poder local, criando estruturas que, algumas vezes, sobrepunham-se à força pública e, em outras, formavam um só corpo de poder (VERAS, 2009).

Nota-se, portanto, que a fundação da Fazenda Boa Vista, em 1830, foi o "motor" que alavancou a ocupação, através da pecuária, nos campos do rio Branco, uma vez que a população estava exclusivamente voltada para a criação e venda de gado, para suprir o mercado local e as regiões do rio Negro e Amazonas (VERAS, 2009).

\section{BOA VISTA: DE FAZENDA À MUNICÍPIO}

Sabe-se que o recorte espaço-temporal é necessário ao entendimento da construção dos elementos históricos que tange pela seara das Ciências Humanas (História, Geografia, Sociologia, Antropologia, entre outras) elevando uma melhor compreensão dos aspectos estruturais (formas e funções dos equipamentos), políticos, sociais e culturais de uma dada civilização e/ou organização social. Cabe, nesse momento, fazer uma análise que se apoiará nu- 
ma perspectiva que segundo Veras $(2009$, p. 55) chama de "dinâmica e estruturação políticoadministrativa: fazenda; freguesia; vila; cidade". Nesse sentido, faz-se uma análise dos conteúdos histórico-geográficos sem cometer prejuízos em desrespeitar o anacronismo histórico.

\section{Cena I - A Fazenda de Boa Vista (1830)}

Com a criação da Fazenda de Boa Vista (Figura 07), em 1830, e a introdução/expansão da pecuária bovina pelo lavrado surgem os primeiros núcleos familiares (índio e não-índio) que aos poucos foram assentando nas terras e legitimando-as em terras rurais que caracterizou-se anos mais tarde em freguesias. Nesse sentido, Moraes \& Gomes Filho afirmam que:

Esta fazenda pecuária estimulou a ocupação em suas proximidades e propiciou o desenvolvimento do porto fluvial na região do Alto Rio Branco. Desta maneira, o marco inicial da cidade foi à construção do edifício-sede da fazenda e da capela sob a invocação de Nossa Senhora do Carmo (2009, p. 143).

Figura 07: Foto do prédio da sede da fazenda Boa Vista e ao fundo a igreja matriz em 1905

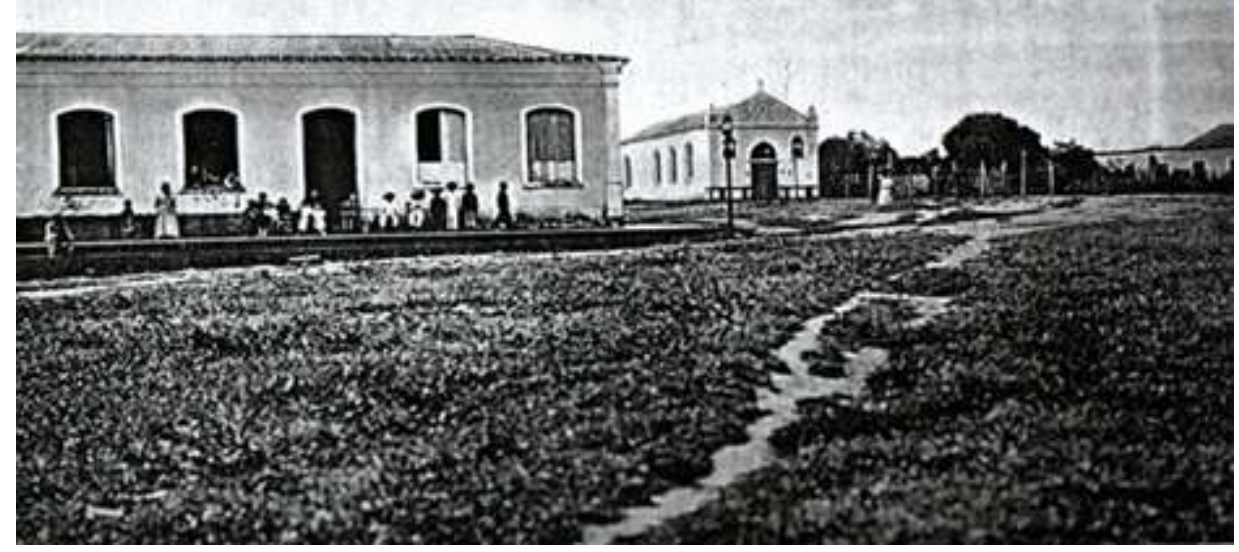

Fonte: Acervo Jaime de Agostinho apud SILVA (2007).

Eleva-se a importância de frisar que nessa região havia um "deserto demográfico", na medida em que a população de migrantes e indígenas estava, "em passos lentos", compondo uma nova dinâmica ocupacional na região, como narra Barbosa:

Em 1858, na tentativa de obter um maior controle administrativo da região em decorrência da presença de forças inglesas na área, foi estabelecida a Freguesia de Nossa Senhora do Carmo (Lei $N^{\circ} .92$ de 09.11.1858) [...] A sede ficou definida no lugar chamado Fazenda de Boa Vista, fundada em 1830 por Inácio Lopes de Magalhães, antigo oficial do Forte São Joaquim [...] Esta ação acompanhava o estímulo do governo provincial em propiciar que particulares se instalassem na região do Rio Branco, através de facilidades na concessão de títulos de terras para criação de gado bovino (Santilli, 1989). Entretanto, não conseguiu fazer com que os grandes espaços fossem preenchidos, favorecendo o desejado papel protetor que o poder público esperava pela presença do fator humano (1993, p. 133). 
Em 18 de setembro de 1850, com o ato da Lei $\mathrm{N}^{\circ}$. 601 (Lei das Terras do Império), o imperador D. Pedro II inicia uma organização dos registros das terras rurais e oito anos depois (em 1858) se definia o local para se instalar uma freguesia devido à existência de um povoado na sede da fazenda Boa Vista (SILVA, 2007; VERAS, 2009).

\section{Cena II - A criação da Freguesia de Nossa Senhora do Carmo (1858)}

O governo imperial, tendo em vista a experiência negativa no início do século XIX em ter perdido território, quase $20.000 \mathrm{~km}^{2}$, no que ficou conhecido como a Questão do Pirara, passou a dar mais proteção e ter mais controle da região amazônica que mais tarde criou-se a província do Amazonas (em 1850) e posteriormente a província designa a criação da freguesia do Nossa Senhora do Carmo (em 1858), pois "havia a necessidade de se criar paliativos para o abandono da área setentrional da província do Brasil Império" (SILVA, 2007, p. 100). Ainda Silva relata que:

\footnotetext{
Segundo o rumo comum da história, a instalação da freguesia ocorre a partir da província do Amazonas [...] Entretanto, em torno desta fazenda e freguesia, foi crescendo o pequeno aglomerado populacional, formando o embrião da vila de Boa Vista do rio Branco (2007, p. 100).
}

Nessa perspectiva, Barbosa (1993) informa que essa fase é marcada por uma aproximação menos violenta entre os remanescentes de índios e o branco (dominador). Isso fez com que a presença do índio se tornasse importante no processo de ocupação, pois a mão de obra indígena auxiliava nas tarefas diárias nas fazendas, bem como o transporte de gado até Manaus, onde o rebanho era então comercializado. Outra questão a ser apontada é que existia um incentivo vislumbrado por um antigo sistema de partilha, onde "a cada quatro cabeças de gado nascidas uma era escolhida pela pessoa encarregada dos tratos nos campos, pode ter estimulado a permanência de uma parte desta população" (SANTILLI, 1989 apud BARBOSA, 1993, p. 134).

Segundo Wallis apud Barbosa cita que "[...] todo o gado do rio Branco não excederá a 10.000 cabeças pertencentes em iguais partes as fazendas nacionais (São Marcos e São Bento) e a particulares" (1993, p. 134).

Nesse sentido, ocorrem os "pequenos" fluxos migratórios destinados a esse povoado, destacam-se os provenientes, principalmente do nordeste brasileiro (do Ceará) que assolados (em 1877) pela seca na região do semiárido nordestino, decidiram migrar para o vale do rio Branco do que enfrentar os seringais no Acre, Pará e Amazonas. Nesse contexto, na região do Rio Branco os migrantes se dedicaram na atividade da pecuária junto aos nativos da região, e que mais tarde implantariam, também, o comércio local fortalecendo, assim, uma estrutura que mais tarde tornaria sede do município (SILVA, 2007).

\section{Cena III - De Freguesia Nossa Senhora do Carmo à condição de Vila Boa Vista do Rio Branco: a criação do município de Boa Vista do Rio Branco (1890)}


Nesse momento, deve-se ressaltar o acontecimento histórico da Proclamação da República no Brasil (em 15 de novembro de 1889) e que, a partir desse fato, uma nova estrutura político-administrativa passa a reger, em território brasileiro, a concepção que se utilizava de província; com isso, passa a ser denominado de Estado. É nesse momento, de mudança, que a província do Amazonas passa a ser denominada estado do Amazonas. Corroborando, Silva afirma que:

Em 1889, ocorre a Proclamação da República, caindo às instituições monárquicas. As províncias são transformadas em Estado. Dessa forma, a província do Amazonas passa a ser denominada e institucionalizada como estado do Amazonas (2005, p. 101).

Em 1890, no dia nove de julho, com o advento da República, por força do Decreto Estadual N ${ }^{\circ}$ 49, o então Governador do estado do Amazonas, Senhor Augusto Ximênes de Ville Roy, criou o município de Boa Vista do Rio Branco, e elevou a Freguesia de Nossa Senhora do Carmo à condição de vila (VERAS, 2009).

Em 04 de novembro de 1892, esse município já se encontrava relacionado entre os municípios do estado do Amazonas pela Lei Estadual $N^{\circ}$. 33, ou seja, passou a ter autonomia administrativa onde os pecuaristas locais vislumbravam a possibilidade de ocupar legalmente as terras (VIEIRA, 2003). Nesse sentido, Silva reforça a ideia colaborando:

\begin{abstract}
No ano de 1890, mais precisamente em 09 de julho, a freguesia foi transformada no município de Boa Vista do Rio Branco, desmembrado do município de Moura do já então estado do Amazonas, sendo a freguesia elevada à categoria de vila, com a denominação de Vila de Boa Vista do Rio Branco, com os mesmos limites da freguesia, isto é, a partir da cachoeira do Bem-Querer no rio Branco para o Norte até a fronteira com a Venezuela e Guiana, mas com o status de vila sede de município. Fabio Barreto Leite foi quem instalou a vila de Boa Vista do Rio Branco, sede do município de mesmo nome (2007, p. 101).
\end{abstract}

Nessa conjuntura política que criou o município de Boa Vista do Rio Branco, o então Governador do Amazonas, citado anteriormente, nomeia o Capitão Fabio Barreto Leite para dar posse às primeiras autoridades do município. No dia 25 de julho de 1890, o então Sargento João Capistrano da Silva Mota, Coronel Mota, foi nomeado como Superintendente, primeiro prefeito de Boa Vista. Já Francisco Coelho e José Joaquim de Souza Júnior foram nomeados como intendentes, ou seja, vereadores (REVISTA DIRETRIZ, 1991 apud VERAS 2009; VIEIRA, 2003).

Segundo Coudreau apud Barbosa (1993), no final do século XIX, o recém-município e proximidades (zona rural) tinha uma população aproximadamente de 1.000 indivíduos, que apresentava uma composição de: brancos (migrantes do Amazonas, Pará e Ceará); índios; mamelucos; dois europeus. Nesse sentido, confirma-se a existência de uma pequena população urbana e uma rural maior que se utilizava da cidade para promover operações comerciais (BARBOSA, 1993). 


\section{CONSIDERAÇÕES FINAIS}

Os caminhos trilhados à compreensão, da gênese, da territorialidade do estado de Roraima necessitaram a conciliação/interseção entres as Ciências Humanas/Sociais, em especial, a Geografia e a História. Nesse viés, analisa-se que não existe uma única Ciência que seja completa ao ponto que possa menosprezar outra, por ser mais jovem, todas as áreas do conhecimento têm o seu valor e ao tentar unir (abstrair o melhor de cada) as Ciências poderão obter facilmente a resposta que tanto se procura para um dado momento histórico (BRAUDEL, 1990).

Nesse sentido, foi relevante utilizar a interdisciplinaridade dessas Ciências, no intuito de entender e fomentar um pensamento que se liga aos fatos, e ao mesmo tempo constrói a percepção de espaço-tempo (Geografia-História), trabalhado na Geografia, na utilização de tabela e figuras (mapas e fotos). Segundo Moraes, “[...] a geografia é uma espécie de ante-ato da história, um mundo de plena naturalidade, a partir do qual (e na relação com o qual) os grupos humanos vão construir suas culturas" (2005, p. 22).

Compreender todo processo de chegada, dos europeus no território brasileiro e entender as mudanças sócio espaciais que ocorreram, não é uma tarefa fácil, tendo em vista que requer tempo para fazer as pesquisas documentais, suas respectivas leituras, análises e sínteses.

Ao pensar nesse artigo, também se fez refletir toda complexidade que o envolve, pois, desenvolver um tema como, territorialidade na Amazônia, logo se percebe a difícil e árdua tarefa, pois os documentos, as estruturas, as formas muitas vezes já foram deterioradas pela ação do tempo, e nasce a parti daí um desafio de se entender um espaço pretérito e compreender o atual espaço geográfico. Conforme Braudel diz que:

O passado é, pois, constituído, numa primeira apreensão, por esta massa de pequenos factos, uns resplandecentes, outros obscuros e indefinidamente repetidos; precisamente aqueles factos, com os quais a microssociologia ou a sociometriacontroem na actualidade o seu bolo quotidiano (existe também uma micro-história). Mas esta massa não constitui toda a realidade, toda a espessura da história, sobre a qual a reflexão científica pode trabalhar à vontade (1990, p. 11).

Contudo, apoiando-se nessas reflexões e buscando alicerce para compreender este artigo, segundo Fernand Braunel (1990, p. 9) menciona que "todo o trabalho histórico decompõe o tempo passado e escolhe as suas realidades cronológicas, segundo preferências e exclusões mais ou menos conscientes". Com esse pressuposto, dar-se a liberdade e cria-se um viés para explicar o processo de ocupação do estado de Roraima, baseado nos parâmetros: sociais; geopolíticos; geoeconômicos, culturais, entre outros.

\section{REFERÊNCIAS}

ARAÚJO, L. J.; PINTO, R. B. A bacia do Rio Branco e os aldeamentos - Século XVIII. In: CAR- 
VALHO, F. et. al. História, cultura e meio ambiente em Roraima: perspectivas interculturais. Boa Vista: Editora UFRR, 2008.

BARBOSA, R. I. Ocupação humana em Roraima I: do histórico colonial ao início do Assentamento Dirigido. Boletim do Museu Paraense Emilio Goeldi, 9 (1): 123-144. Belém, 1993-1.

BRAUDEL, F. Histoireetsciencessociales. Paris: EditionsFlamarion, 1990.

CAMPOS, C. Diversidade socioambiental de Roraima: subsídio para debater o futuro sustentável da região. São Paulo: Instituto socioambiental, 2011.

FARAGE, N. As muralhas dos sertões: os povos indígenas no rio Branco e a colonização. Rio de Janeiro: Paz e Terra, 1991.

FERRI, P. Achados ou perdidos? A migração indígena em Boa Vista. Goiás: MLAL, 1990.

GALEANO, E. As veias abertas da América Latina. 14ạ edição. Rio de Janeiro: Paz e Terra, 1979.

INSTITUTO BRASILEIRO DE GEOGRAFIA E ESTATÍSTICA - IBGE. Censo de 2010. Disponível em <www.ibge.gov.br>. Acesso em: 05. abr. 2013.

MORAES, A. C. R. Território e história no Brasil. São Paulo: Annablume, 2005.

MORAES, C. G. M. S. M.; GOMES FILHO, G. F. Visadas sobre Boa Vista do Rio Branco: razões e inspirações da capital de Roraima (1830 - 2008). Tempos históricos. Volume 13, 1․ semestre, 2009, p. 137-166.

PAVANI, J. D.; MOURA, G. Panorama fotográfico urbanístico e arquitetônico de Boa Vista. Brasília: Gráfica Coronário, 2006.

RIBEIRO, D. O povo brasileiro: A formação e o sentido do Brasil. 2. ed. Curitiba: Companhia das letras, 1995.

RORAIMA. Guia turístico Roraima: ecológico, histórico e cultural. São Paulo: Empresa das Artes, 2009.

SILVA, P. R. F. Dinâmica territorial urbana em Roraima - Brasil. 2007. 329 f. Tese (Doutorado em Geografia - Programa de Pós-Graduação em Geografia Humana), Universidade de São Paulo, São Paulo, 2007.

VALE, A. L. F. O “Ceará" em Roraima: migrações de cearenses - 1980 a 1999. Jaboticabal: Funep, 2005.

VERAS, A. T. R.A produção do espaço urbano de Boa Vista - Roraima. 2009. 235 f. Tese (Doutorado em Geografia - Programa de Pós-Graduação em Geografia Humana), Universidade de São Paulo, São Paulo, 2009.

VIEIRA, J. G. Missionários, fazendeiros e índios em Roraima: a disputa pela terra - 1777 a 1980. 2009. 235 f. Tese (Doutorado em História - Programa de Pós-Graduação em História), Universidade Federal de Pernambuco, Recife, 2003.

Artigo recebido em 01 de março de 2018.

Aprovado em 24 de abril de 2018. 